Atıf İçin: Mut Z, Erbaş Köse ÖD, Akay H, Sezer E, 2021. Orta ve Batı Karadeniz Bölgesinden Toplanan Yerel Yulaf Genotiplerinin Bazı Özelliklerinin Değerlendirilmesi. Iğdır Üniversitesi Fen Bilimleri Enstitüsü Dergisi, 11(2): 1582-1594.

To Cite: Mut Z, Erbaş Köse ÖD, Akay H, Sezer E, 2021. Evaluation of Some Characteristics of Local Oat Genotypes Collected from the Central and Western Black Sea Region. Journal of the Institute of Science and Technology, 11(2): 15821594.

\title{
Orta ve Batı Karadeniz Bölgesinden Toplanan Yerel Yulaf Genotiplerinin Bazı Özelliklerinin Değerlendirilmesi
}

\section{Zeki MUT ${ }^{1}$, Özge Doğanay ERBAŞ KÖSE ${ }^{*}$, Hasan AKAY², İsmail SEZER ${ }^{2}$}

ÖZET: Bu çalışmada, Orta ve Batı Karadeniz bölgesinde 10 ilden (Düzce, Bolu, Zonguldak, Karabük, Kastamonu, Ordu, Sinop, Samsun, Amasya ve Tokat) toplanan 251 adet yulaf populasyonu ve 4 adet yulaf çeşidi kullanılmıştır. İki yıllık çalışma sonuçlara göre, bütün incelenen özellikler bakımından yıllar ve genotipler arasında önemli farklar olduğu belirlenmiştir. Yı1 $\times$ genotip interaksiyonu sadece salkımda başakçık sayısı, salkımda tane sayısı, salkımda tane ağırlı̆̆ arasında oldukça geniş varyasyon tespit edilmiş ve genotiplerin salkım uzunluğu 21.27 ile $37.70 \mathrm{~cm}$, salkımda başakçık sayısı 26.08 ile 75.35 adet, başakçıkta tane sayısı 1.64 ile 2.43 adet, salkımda tane sayısı 51.54 ile 155.00 adet, salkımda tane ağırlığı 1.44 ile $4.85 \mathrm{~g}$, bin tane ağırlığ 18.55 ile $38.41 \mathrm{~g}$, tane boyu 9.81 ile $15.72 \mathrm{~mm}$, tane eni 1.96 ile $2.94 \mathrm{~mm}$, iç oranı \% 51.85 ile 77.78 ve dış kavuz uzunluğu 18.12 ile $29.76 \mathrm{~mm}$ arasında değişmiştir.

Anahtar Kelimeler: Yulaf, yerel çeşit, toplama, salkım

\section{Evaluation of Some Characteristics of Local Oat Genotypes Collected from the Central and Western Black Sea Region}

\begin{abstract}
In this study, 251 oat populations and 4 oat cultivars collected from 10 provinces (Düzce, Bolu, Zonguldak, Karabük, Kastamonu, Ordu, Sinop, Samsun, Amasya ve Tokat) in the Central and Western Black Sea region were used. According to the results of the two-year, it was determined that there were significant differences between years and genotypes in terms of all characteristics examined. Year $\times$ genotype interaction was found to be significant only for the number of spikelet per panicle, the number of kernels per panicle, kernel weight per panicle, kernel length and groat percentage. In the study, a large variation was determined among genotypes in terms of characteristics examined, and the panicle length ranged from 21.27 to $37.70 \mathrm{~cm}$, number of spikelet per panicle from 26.08 to 75.35 pieces, number of kernel per spikelet from 1.64 to 2.43 pieces, number of kernel per panicle from 51.54 to 155.00 pieces, kernel weight per panicle from 1.44 to $4.85 \mathrm{~g}$, thousand-kernel weight from 18.55 to $38.41 \mathrm{~g}$, kernel length from 9.81 to $15.72 \mathrm{~mm}$, kernel width from 1.96 to $2.94 \mathrm{~mm}$, groat percentage 51.85 to $77.78 \%$ and glume length from 18.12 to $29.76 \mathrm{~mm}$.
\end{abstract}

Keywords: Oat, local cultivar, collecting, panicle

${ }^{1}$ Zeki MUT (Orcid ID: 0000-0002-1465-3630), Özge Doğanay ERBAŞ KÖSE (Orcid ID: 0000-0003-0429-3325), Bilecik Şeyh Edebali Üniversitesi, Ziraat ve Doğa Bilimleri Fakültesi, Tarla Bitkileri Bölümü, Bilecik, Türkiye

${ }^{2}$ Hasan AKAY (Orcid ID: 0000-0003-1198-8686), İsmail SEZER (Orcid ID: 0000-0002-8407-7448), Ondokuz May1s Üniversitesi, Ziraat Fakültesi, Tarla Bitkileri Bölümü, Samsun, Türkiye

*Sorumlu Yazar/Corresponding Author: Özge Doğanay ERBAŞ KÖSE, e-mail: ozgedoganay.erbas@bilecik.edu.tr 


\section{GİRiş}

Poaceae familyanda yer alan yulaf (Avena sativa L., 2n=42), yılda yaklaşık 23.1 milyon ton üretimi ile Dünya tahıl üretiminde altıncı sırada yer almaktadır (Anonim, 2019a). Türkiye'de ise 265 bin ton üretime sahiptir (Anonim, 2019b). Dünyada yulafın Avena sativa, Avena byzantina ve Avena nuda olmak üzere üç hexaploid türünün yetiştiriciliği yapılmaktadır (Webster, 2012).

Yulaf çoğunlukla tanesi ve otu hayvan beslemede kullanılmak amacıyla yetiştirilir. Yulaf tanesinin yüksek miktarda protein, çözünür lif ( $\beta$-glukanlar), doymamış yağ asitleri, vitamin, mineral ve antioksidanları içermesi ve bu besinsel maddelerin insan sağlı̆ğ üzerine öneminin anlaşılmasıyla insan gıdası olarak ve gıda sanayinde kullanımı artmaktadır (Buerstmayr ve ark., 2007). Ayrıca, kötü kolesterolü düşürmesi ve kalp-damar rahatsızlıklarını azaltması gibi sağlık üzerine etkileri de yulafa olan ilgiyi artırmakta ve onu değerli bir ürün haline getirmektedir (Finnan ve ark., 2019).

Dünya çapında 200.000 'den fazla yabani ve tarımı yapılan Avena türü tohum gen bankalarında saklanmaktadır (Diederichsen, 2008). Bu tohumlar, yerel çeşitler, bunların yabani akrabaları, artık günümüzde yetiştirilmeyen eski çeşitler ve genetik özellikleri belirlenmiş genotiplerden oluşmaktadır. Akdeniz ve Yakın Doğu gen merkezlerinin kesişme noktasında yer alan Türkiye, genetik çeşitlilik ve gen kaynakları yönünden oldukça zengindir (Çalışkan ve Koç, 2019). Ancak, ülkemizde hızla artan nüfus, gelişen teknoloji ve endüstrileşme, artan yapılaşma, köyden kente göç gibi çevresel problemlerle birlikte insanların bilinçsiz ve duyarsız davranışları, tarım yapılan toprakların hızla ve üzerindeki doğal zenginlikleri ile kaybolmasına neden olmaktadır.

Ülkemize paralel olarak tüm dünyada da benzer problemlerin yaşanması ve bunların bazı kurumlar tarafından fark ediliyor olması, son yıllarda doğal kaynakların muhafazası ve korunmasına yönelik yapılan çalışmaların artırılması ve desteklenmesini sağlamaktadır. Çünkü bir ülkenin zenginliği sahip olduğu doğal kaynaklara dayalıdır ve biyolojik zenginlikte canlı doğal kaynakların çeşitliliği ile ölçülür. Biyolojik çeşitlilik, başta gıda olmak üzere insanların temel ihtiyaçlarını karşılamasında vazgeçilmez bir yere ve öneme sahiptir. Kültürü yapılan beyaz yulafın (Avena sativa L.) ve kırmızı yulafın (Avena byzantina Koch.) kökeninin Anadolu olduğu belirtilmekte ve ülkemizin yulaf form ve çeşit zenginliği bakımından özel bir önem taşıdığı bildirilmiştir (Kün, 1988).

Yulaf ıslahında genetik havuzunda yararlı genler sağlayabilecek genotiplerin muhafaza edilmesi, karakterize edilmesi ve kullanılması büyük önem taşımaktadır. Dünyada ve ülkemizde çok sayıda yulaf çeşidi, yerel çeşitlerden seçilen tek bitkilerden veya bu yerel çeşitlerin yer aldığı melezlerden elde edilmiştir (Nikoloudakis ve ark., 2016). Islahçılar tane verimini arttırmak için verimi etkileyen morfolojik ve bazı tanımlayıcı özelliklerinin belirlenmesinin seleksiyonda etkinliği artırmak için çok önemli olduğunu bildirmişlerdir (Vaisi ve Golparvar, 2013; Batalova ve ark., 2010; Mut ve ark., 20018b).

Bu çalışma, Orta ve Batı Karadeniz bölgesinden toplanan 251 yulaf genotipi ile 4 standart çeşidinin salkım uzunluğu, salkımda başakçık sayısı, başakçıkta tane sayısı, salkımda tane sayısı, salkımda tane ağırlığı, bin tane ağırlığı, tane boyu, tane eni, iç oranı ve dış kavuz uzunluğu bakımından varyasyonunu belirlemek amacıyla iki yıl süreyle yürütülmüştür.

\section{MATERYAL VE METOT}

Çalışmada, Orta ve Batı Karadeniz bölgesindeki 10 ilden toplanan 251 yulaf populasyonu ile 4 standart çeşit kullanılmıştır. Bu genotiplerden 1-11 numaralı genotipler Düzce (11 adet), 12-52 numaralı genotipler Bolu (41 adet), 53-99 numaralı genotipler Zonguldak (47 adet), 100-111 numaral1 genotipler Karabük (12 adet), 112-141 numaralı genotipler Kastamonu (30 adet), 142-147 numaralı genotipler Ordu (6 adet), 148-168 numaralı genotipler Sinop (21 adet), 169-216 numaralı genotipler Samsun (48 
adet), 217-230 numaralı genotipler Amasya (14 adet) ve 231-251 numaralı genotipler ise Tokat (21 adet) illerinden toplanmıştır. Denemelerde standart çeşit olarak Faikbey, Seydişehir, Yeşilköy-330 ve Yeşilköy-1779 çeşitleri kullanılmıştır.

Toplanan örnekler Ondokuz Mayıs Üniversitesi Ziraat Fakültesi deneme alanında 2008-2009 ve 2009-2010 yetiştirme sezonlarında Augmented deneme desenine (Federer, 2005) göre standart çeşitlerin $12 \mathrm{kez}$ tekrarlanarak 2 yıl süreyle yetiştirilmiştir. Ekim işlemi her iki yılda da $\mathrm{m}^{2}$ de 450 canlı tohum bulunacak şekilde 6 metre uzunluğundaki parsellere $20 \mathrm{~cm}$ sira aralığında 4 sira olacak şekilde, birinci yıl 18.11.2008 ve ikinci yıl 05.11.2009 tarihinde elle yapılmıştır. Yabancı ot mücadelesi kardeşlenme döneminde herbisit (Tribenuran-metil (DF) \%75) kullanılarak yapılmıştır. Ekimle birlikte dekara $13 \mathrm{~kg}$ Di-amonyum fosfat (DAP) ile $8 \mathrm{~kg}$ amonyum nitrat $(\% 33 \mathrm{~N}$ ) gübresi verilmiştir. Kardeşlenme döneminde $13 \mathrm{~kg}$ amonyum nitrat (\% $33 \mathrm{~N})$ üst gübre olarak uygulanmıştır. Hasat işlemi her iki yılda da Haziran ayında orakla toprak yüzeyinden $5 \mathrm{~cm}$ yükseklikten biçilerek yapılmıştır. Hasat sonrası 3-5 gün parsellerde kurumaya bırakılan örnekler parsel harman makinesi ile harmanlanmıştır.

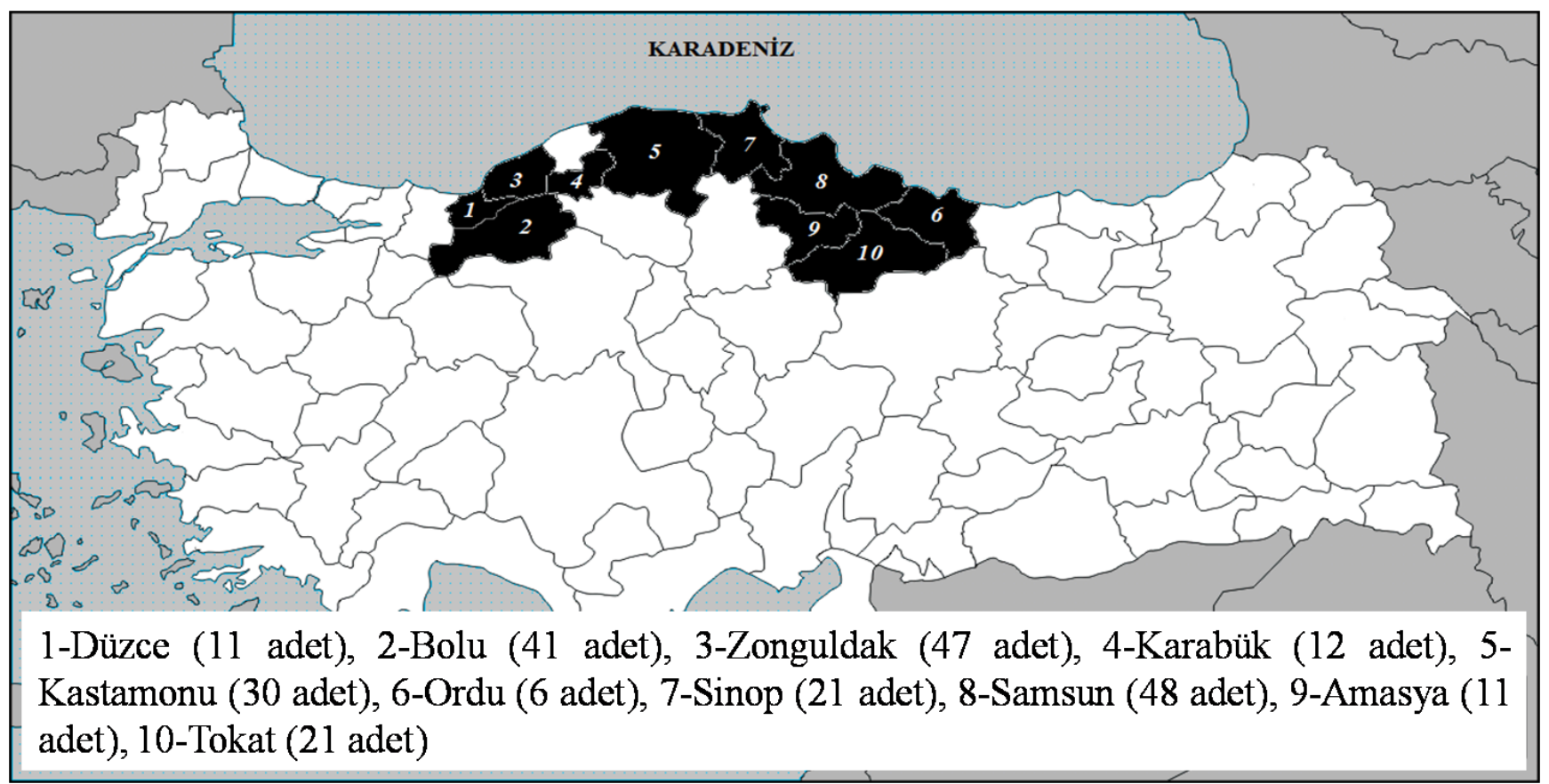

Şekil 1. Orta ve Batı Karadeniz Bölgesinde Tohum Toplanan İller

Samsun ilinin yulaf yetiştirme dönemine ait uzun yıllar yağış toplamı $498 \mathrm{~mm}$, çalışmanın yürütüldüğü 2008-2009 ve 2009-2010 yıllarına ait yağış toplamları sırasıyla $553 \mathrm{~mm}$ ve $635 \mathrm{~mm}$ olmuştur. Uzun yıllara, 2008-2009 ve 2009-2010 yetiştirme dönemine ait ortalama sıcaklıklar sirasıyla 12,13 ve $14{ }^{\circ} \mathrm{C}$ olmuştur.

Deneme alanı topraklarının bazı fiziksel ve kimyasal özelliklerini tespit etmek üzere ekim öncesi 0-40 cm derinlikten alınan toprak örnekleri alınmıştır. Her iki yılda da deneme alanı toprağının killi bir bünyeye sahip, tuzsuz, fosfor içeriğinin iyi ve potasyum içeriğinin düşük olduğu görülmektedir. Deneme alanı toprağının birinci yıl pH bakımından nötr, kireçsiz organik madde bakımından orta seviyede, ikinci yıl ise $\mathrm{pH}$ bakımından hafif alkali, kireçli ve organik madde bakımından iyi seviyede olduğu tespit edilmiştir.

Bu çalışamada, 10 bitkide belirlenen salkım uzunluğu ana saptaki salkımın ilk boğumu ile son boğumu arasındaki uzunluk cm olarak, salkımda başakçık sayısı her salkımdaki tüm başakçıklar 
sayılarak adet olarak, başakçıkta tane sayısı salkımdaki taneler sayılıp salkımdaki başakçık sayısına oranlanarak adet olarak, salkımda tane sayısı salkımdaki tüm taneler sayılarak adet olarak, salkımda tane ağırlı̆gı ise salkımdaki tanelerin ağırlıklarının hassas terazide tartılmasıyla g olarak belirlenmiştir. $\mathrm{Bu}$ salkımlardan elde edilen 25 başakçıkta kavuzların uzunluğu dijital kumpas ile ölçülerek dış kavuz uzunluğu mm olarak ölçülmüştür. Tane boyu ve eni bu salkımlardan elde edilen 25 adet kavuzlu tanenin boyu ve ölçülerek mm olarak belirlenmiştir (Şekil 2). İç oranı 40 adet tane kavuzlarından ayrılmış kavuzsuz taneler tartılarak toplam ağırlığa oranlanmış ve \% olarak ifade edilmiştir. Bin tane ağırlığı her parselden elde edilen örneklerden 4 defa 100 'er tane sayılarak tartılmış, ortalaması alınarak 10 ile çarpılmış ve g olarak ifade edilmiştir.

Denemede elde edilen veriler kullanılarak, popülasyonun genel durumunu tanımlamak amaciyla özelliklere ait ortalamaların dağılımları (histogram grafikleri), elde edilen verilerin yıllar üzerinden birleştirilmiş varyans analizleri ve incelenen özellikleri arasındaki Pearson korelasyon katsayıları JMP07 paket programında hesaplanmıştır (JMP, 2007).

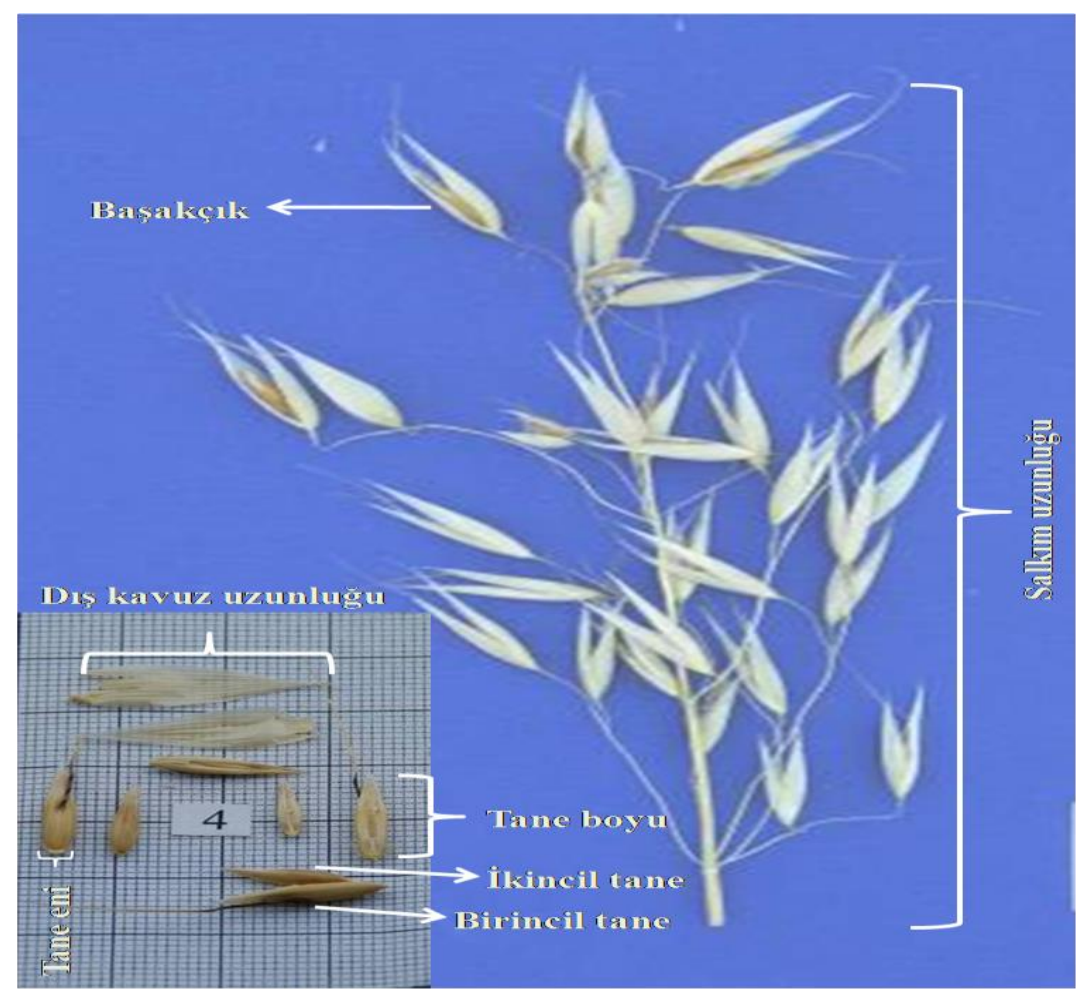

Şekil 2. Yulaf salkımının kısımları

\section{BULGULAR VE TARTIŞMA}

İncelenen bütün özellikler bakımından genotipler ve y1llar arasında önemli $(\mathrm{P}<0.01)$ farklar belirlenmiştir. Salkımda başakçık sayısı, salkımda tane sayısı, salkımda tane ağırlığı, tane boyu ve iç oranı üzerine ise yıl $\times$ genotip interaksiyonun etkisi önemli bulunmuştur (Çizelge 1).

Çalışmada, salkım uzunluğu, salkımda başakçık sayısı, başakçık tane sayısı, salkımda tane sayısı, salkımda tane ağırlığı ve bin tane ağırlığının ortalama dağılımlarını gösteren histogram grafikleri ve tanımlayıcı verileri Şekil 3'de, tane boyu, tane eni, iç oranı ve dış kavuz uzunluğunun ortalama dağılımlarını gösteren histogram grafikleri ve tanımlayıcı verileri Şekil 4'de verilmiştir. Yıllara göre genopilerin incelenen özelliklerine ait ortalama değerler Şekil 5'de verilmiştir. En yüksek ve en düşük değerleri gösteren beşer genotip Çizelge 2'de verilmiştir. Bu çalışmada incelenen özellikler yulaf ıslah programlarında düzenli olarak ölçülen önemli kriterlerdir (Boyle ve ark., 2015). 
Çizelge 1. İncelenen özelliklere ait yıllara, genotiplere ve y1l x genotip interaksiyonlarına ait kareler ortalaması ve önemlilikleri

\begin{tabular}{llll}
\hline Varyasyon kaynağı & Yıl $(\mathrm{Y})$ & Genotip $(\mathrm{G})$ & $\mathrm{Y} \times \mathrm{G}$ interaksiyonu \\
\hline Serbestlik derecesi & 1 & 254 & 254 \\
\hline Salkım uzunluğu & $1373.1^{* *}$ & $27.96^{* *}$ & 11.15 \\
Salkımda başakçık sayısı & $537.48^{* *}$ & $194.67^{* *}$ & $94.72^{* *}$ \\
Başakçıkta tane sayısı & $56.03^{* *}$ & $0.21^{* *}$ & 0.02 \\
Salkımda tane sayıs1 & $147804.56^{* *}$ & $743.39^{* *}$ & $425.25^{* *}$ \\
Salkımda tane ağırlığ & $202.13^{* *}$ & $0.46^{* *}$ & $0.32^{* *}$ \\
Bin tane ağırlığı & $1867.33^{* *}$ & $25.35^{* *}$ & 7.33 \\
Tane boyu & $357.40^{* *}$ & $2.06^{* *}$ & $1.32^{* *}$ \\
Tane eni & $0.19^{* *}$ & $0.06^{* *}$ & 0.02 \\
Tanelkavuz oranı & $1212.43^{* *}$ & $21.21^{* *}$ & $13.42^{* *}$ \\
Dış kavuz uzunluğu & $1413.87^{* *}$ & $14.96^{* *}$ & 2.83 \\
\hline
\end{tabular}

** $P<0.01$

\section{Salkım Uzunluğu}

Çalışmada salkım uzunluğu bakımından genotipler ve yıllar arasında önemli $(\mathrm{P}<0.01)$ farklar belirlenmiştir. Genotiplerin salkım uzunluğu 21.27 (G145) ile 37.70 (G187) cm arasında değişmiş ve ortalama $28.99 \mathrm{~cm}$ olmuştur. Genotiplerin \% 25'inin (64 genotip) salkım uzunluğu 28-30 cm sınıf aralığında yoğunlaşmıştır (Şekil 3). Salkım uzunluğu ortalaması toplanan populasyonlarda $(29.07 \mathrm{~cm})$ çeşitlerden $(24.05 \mathrm{~cm}$ ) daha uzun olmuştur (Şekil 3). Salkım uzunluğu birinci yıl ikinci yıldan daha uzun gerçekleşmiştir (Şekil 5). Yapılan çalışmalarda salkım uzunluğu bakımından genotipler arasında önemli farkların olduğu bildirilmiştir (Dumlupınar ve ark., 2017; Çalışkan ve Koç, 2019). Salkım uzunluğunu Erbaş ve Mut (2013) 16.9 ile $25.0 \mathrm{~cm}$, Brunava ve ark., (2014) birinci yıl $17.0 \mathrm{~cm}$ ve ikinci y1l $16.0 \mathrm{~cm}$ olarak bildirmişlerdir. Kazıu ve ark. (2019) yaptıkları çalışmada salkım uzunluğunun 26.0 ile $37.0 \mathrm{~cm}$ arasında değiştiğini ve uzun salkım uzunluğuna sahip çeşitlerin tane verimlerinin de yüksek olduğunu bildirmişlerdir. Ayrıca, aynı araştırıcılar salkım uzunluğuna genotipin daha fazla etki ettiğini bildirmişlerdir.

\section{Salkımda Başakçık Sayısı}

Yapılan birleştirilmiş varyans analizi sonuçlarına göre salkımda başakçık sayısının yıl, genotip ve y1l $\times$ genotip interaksiyonundan istatistiki olarak \%1 önemlilik seviyesinde etkilendiği belirlenmiştir (Çizelge 1). Genotiplerin salkımda başakçık sayısı 26.08 (G131) ile 75.35 (G135) adet arasında değişmiştir. Genotiplerin \% 19'unun (49 genotip) salkımda başakçık sayısı 40-45 adet sınıf aralığında değişmiştir. Salkımda başakçık sayısı ortalaması 44.83 adet ve populasyonların ortalaması (45.02 adet) çeşitlerin ortalamasından (33.25 adet) daha yüksek olmuştur (Şekil 3). Salkımda başakçık sayısı birinci yıl 45.90 adet, ikinci y1l 43.77 adet olmuştur (Şekil 5). Erbaş ve Mut (2013) 121 yulaf genotipi ile yaptıkları çalışmada salkımda başakçık sayısının genotipler arasında önemli farklar gösterdiğini ve ortalama 26.3 adet olduğunu bildirmiştir. Yapılan diğer çalışmalarda salkımda başakçık sayısı 38.5 ile 107.7 adet (Mut ve ark., 2011), 42.33 ile 125.67 adet (Kapoor ve ark., 2011), 60.78 ile 102.11 adet (Krishna ve ark., 2014) ve 39.2 ile 49.7 (Batalova ve ark., 2015) arasında değişmiştir. 

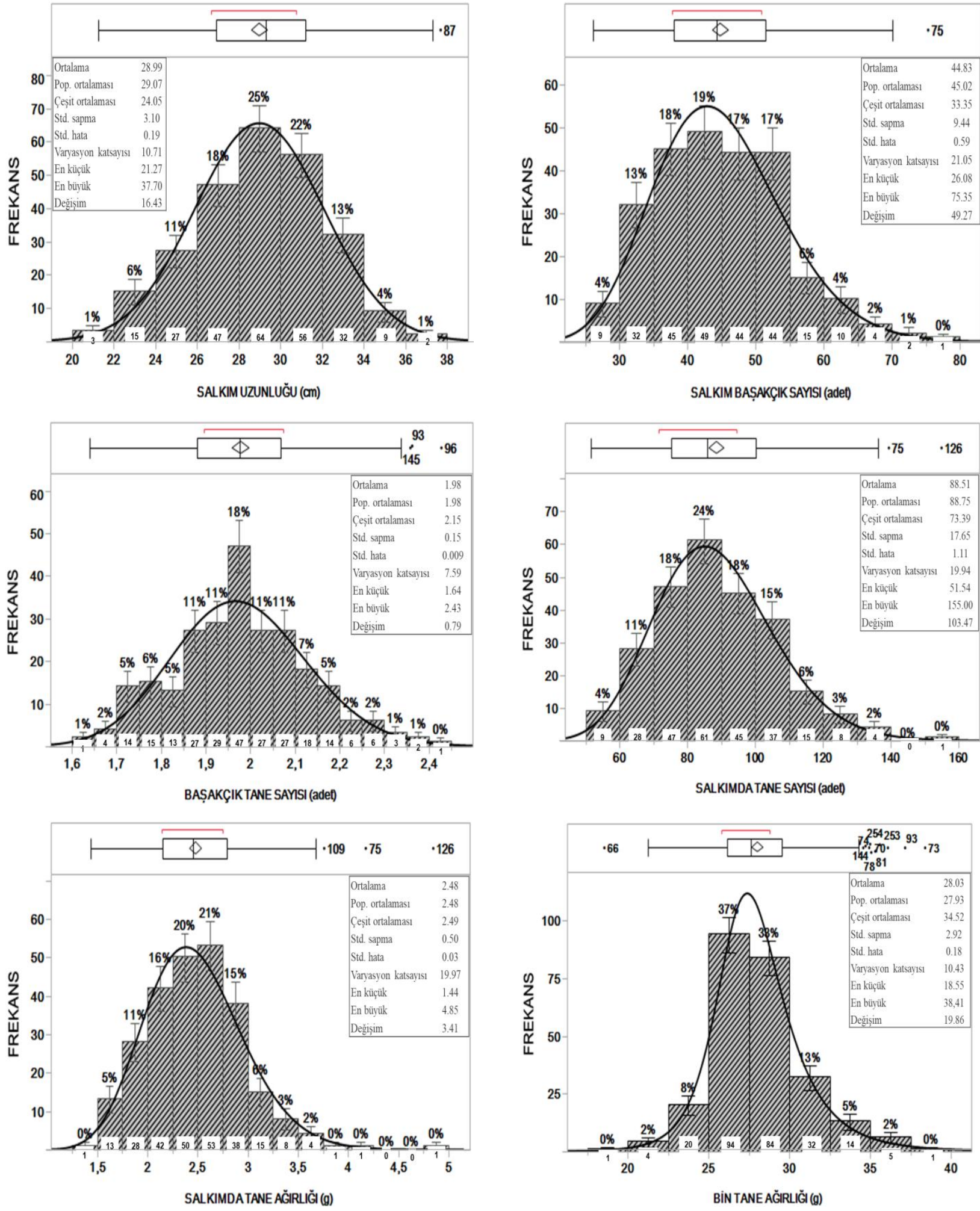

Şekil 3. 255 adet yulaf genotipinin salkım uzunluğu, salkımda başakçık sayısı, başakçıkta tane sayısı, salkımda tane sayısı, salkımda tane ağırlığı ve bin tane ağırlığını gösteren histogram grafikleri ve tanımlayıcı istatistik verileri

\section{Başakçıkta Tane Sayısı}

Birleştirilmiş varyans analizine göre, başakçıkta tane sayısı bakımından yıllar ve genotipler arasında önemli $(\mathrm{P}<0.01)$ farklar belirlenmiştir. Genotiplerin başakçıkta tane sayısı 1.64 (G11) ile 2.43 (G96) adet arasında değişmiş ve ortalama 1.98 adet olmuştur. Genotiplerin \%18'inin (47 gnotip) başakçıkta tane sayısı 1.85-2.0 adet sınıf aralığında değer göstermiştir. 
Başakçıkta tane sayısı ortalaması çeşitlerde 2.15 adet iken, popülasyonlarda 1.98 adet olarak belirlenmiştir (Şekil 3). Şekil 5'e göre, başakçıkta tane sayısı birinci yıl 2.31 adet, ikinci yıl 1.35 adet olmuştur (Şekil 5). Kültürü yapılan yulafların çoğunda (Avena sativa L. ve Avena byzantina L.) başakçık başına iki adet çiçek bulunur. Fakat bazı genotiplerde başakçıkta üç çiçek bulunur ki bu durum kalıtsal bir özelliktir (McBratney ve Frey, 1983). Bu çiçeklerin oluşturduğu tanelerin iriliği dipten üsttekine gidildikçe azalmaktadır (Kün, 1988). Yapılan birçok çalışmada başakçıkta tane sayısı bakımından genotipler arasında önemli farklar olduğu bildirilmiştir (Vilaró ve ark., 2004; Erbaş ve Mut, 2013). Vilaró ve ark. (2004) birçok yulaf çeşidi ile yaptıkları çalışmada başakçıkta tane sayısının 1.91 ile 2.92 adet arasında değiştiğini bildirmişlerdir.

\section{Salkımda Tane Sayısı}

Salkımdaki tane sayısı yulafta tane verimi için önemli bir özelliktir. Yapılan birleştirilmiş varyans analizi sonuçlarına göre salkımda tane sayısının yıllara ve genotiplere göre istatistiki olarak \% 1 seviyesinde önemli olduğu ve salkımda tane sayısına yıl $\times$ genotip interaksiyonun etkisinin önemli $(\mathrm{P}<0.01)$ bulunduğu belirlenmiştir (Çizelge 1). Çalışmada genotiplerin salkımda tane sayısı 51.54 (G244) ile 155.00 adet (G126) arasında değişmiştir. Salkımda tane sayısı bakımından çeşitlerin ortalaması (73.39 adet) genel ortalamanın (88.51 adet) altında, popülasyonların ortalaması (88.75 adet) genel ortalamanın üstünde bulunmuştur. Genotiplerin \% 24'ünün (81 genotip) salkımda tane sayısının 80-90 adet sınıf aralığında yer aldığı tespit edilmiştir (Şekil 3). Genotiplerin salkımda tane sayısı ortalaması birinci y1l 105.49 adet ikinci yıl ise 71.52 adet olarak gerçekleşmiştir (Şekil 5). Salkımda tane sayısının seleksiyonda en uygun kriter olabileceği bildirilmiştir (Sürek ve Valentine, 1996). Batalova ve ark. (2010) salkımda tane sayısının kalıtımının yüksek olduğunu bildirmişlerdir. Dumlupınar ve ark. (2011) yerel yulaf genotipleri ile yaptıkları çalışmada salkımdaki tane sayısının genotip ve yıllardan etkilendiğini, bu özelliğin 59.0 ile 196.40 adet arasında değiştiğini bildirmişlerdir. Dumlupınar ve ark. (2012) 17 yulaf genotipinde yaptıkları çalışmada, salkımda tane sayısının tane verimine \% 34.30, bitki boyuna \% 10.52, salkımda tane ağırlığına \% 44.57 ve bin tane ağırlığına \% 8.08 oranında etki ettiğini bildirmişlerdir. Yapılan diğer çalışmalarda salkımda tane sayısı 58.7 ile 167.9 adet (Mut ve ark., 2011), 10 ile 198 adet (Dumlupınar ve ark., 2017) ve 93.7 ile 153.6 adet (Kaziu ve ark., 2019) arasında değişmiştir.

\section{Salkımda Tane Ăğırlığı}

Birleştirilmiş yılların analizine göre, salkımda tane ağırlı̆̆ bakımından yıllar ve genotipler arasında önemli farklar belirlenmiştir. Yı1 $\times$ genotip interaksiyonunuda bu özellik bakımında istatistiki olarak önemli $(\mathrm{P}<0.01)$ bulunmuştur (Çizelge 1). Genotiplerin salkımda tane ağırlığı 1.44 (G149) ile $4.85 \mathrm{~g}$ (G126) arasında değişmiş ve ortalama $2.48 \mathrm{~g}$ olmuştur. Salkımda tane ağırlığının en yoğun olduğu sınıf aralığı 2.25 ile 2.75 g olmuş ve bu sınıflarda 103 genotip yer almıştır. Salkımda tane ağırlığ ortalaması bakımından çeşitler (2.49 g) ve populasyonlar (2.48 g) yakın değerler göstermiştir (Şekil 3). Salkımda tane ağırlığı birinci yıl (3.11 g) ikinci yıldan (1.85 g) daha yüksek değerlere sahip olmuştur (Şekil 5). Daha önce yapılan çalışmalarda ıslahçıların tane verimini arttırabilmek için bu özelliği dikkate alabilecekleri bildirilmiştir (Sawicki, 1984). Mut ve ark. (2011) dünyanın farklı yerlerinden 81 yulaf çeşidi ile farklı lokasyonlarda yaptıkları çalışmada, salkımda tane ağırlığının hem genotip hem de çevreden etkilendiğini ve 1.90 ile 4.97 g arasında değiştiğini bildirmişlerdir. Dumlupınar ve ark. (2017)'da 384 yerel yulaf genotipi ile yaptıkları çalışmada genotiplerin salkımda tane ağırlığının 0.53 ile $4.23 \mathrm{~g}$ arasında değiştiğini, Kutlu ve Gülmezoğlu (2020) ise farklı tarımsal uygulamaların ve ekim zamanının salkımda tane ağırlığı üzerine etkili olduğunu bildirmişlerdir. 


\section{Bin tane ă̆ırlı̆̆ı}

Bin tane ağırlığı tanenin büyüklüğünü ve besin değerini tanımlamaktadır. Çalışmada genotip ve yıllar arasında bin tane ağırlığı bakımından önemli $(\mathrm{P}<0.01)$ farklar olduğu tespit edilmiştir (Çizelge 1). Genotiplerde bin tane ağırlığı 18.55 (G66) ile 38.41 g (G73) arasında değişmiş ve ortalama $28.03 \mathrm{~g}$ olmuştur. Bin tane ağırlığı en yoğun 20 ile $30 \mathrm{~g}$ (178 genotip) sınıf aralığında belirlenmiş ve 52 genotip 30 g'ın üstünde bin tane ağırlığına sahip olmuştur (Şekil 3). Bin tane ağırlığı ortalaması çeşitlerde 34.52 g ile populasyonlardan (27.93 g) daha yüksek (Şekil 3), birinci yıl (29.98 g) ise ikinci yıldan (Şekil 5) daha yüksek gerçekleşmiştir. Bu özellik genotip farklılıklarından, yetiştirme koşullarından ve uygulanan tarımsal işlemlerden etkilenmektedir (Mut ve ark., 2018a; Kaziu ve ark., 2019; Kutlu ve Gülmezoğlu, 2020). Bin tane ağırlığı bakımından çeşitler arasında önemli varyasyon ve yüksek kalıtım gözlendiğini bildirilmiştir (Dumlupınar ve ark., 2017; Mut ve ark. 2018a).Yapılan çalışmalarda bin tane ağırlığının 20.9 ile 53.01 g arasında değiştiği bildirilmiştir (Vilaró ve ark., 2004; Buerstmayr ve ark., 2007; Mut ve ark., 2016).

\section{Tane Boyu ve Tane Eni}

Çalışmada tane boyu ve tane eni bakımından yıl ve genotipler arasında önemli farklılıklar belirlenmiştir. Ayrıca tane boyu üzerine yıl $\times$ genotip interaksiyonununda istatistiki olarak önemli olduğu görülmüştür. Genotiplerin tane boyu ve eni sırasıyla 9.81 (G146) ile $15.72 \mathrm{~mm}$ (G73) arasında ve 1.96 (G128) ile $2.94 \mathrm{~mm}$ (G195) arasında değişmiştir. Tane boyu ve eni ortalaması sırasıyla 12.61 $\mathrm{mm}$ ve $2.44 \mathrm{~mm}$ olarak belirlenmiştir. Tane boyu ve eni çeşitlerde sırasıyla $12.65 \mathrm{~mm}$ ve $2.25 \mathrm{~mm}$, popülasyonlarda ise sırasıyla $12.06 \mathrm{~mm}$ ve $2.45 \mathrm{~mm}$ olarak ölçülmüştür. Genotipler en yoğun tane boyuna 12.5 ile $13.0 \mathrm{~mm}$ (59 genotip) sınıf aralığında, tane enine ise 2.4 ile $2.5 \mathrm{~mm}$ (90 genotip) sinıf aralığında sahip olmuşlardır (Şekil 4). Genotiplerin birinci ve ikinci yıl tane boyu sırasıyla $13.46 \mathrm{~mm}$ ve $15.78 \mathrm{~mm}$ ve tane eni sırasıyla $2.47 \mathrm{~mm}$ ve $2.42 \mathrm{~mm}$ olmuştur (Şekil 5).

Tane boyutu, tane ağırlığı ile ilişkili olduğu için yulafta önemli bir verim bileşenidir (Koeyer ve ark., 1993). Yulaf tanelerinin boyutu, yulafın ticari değerinin belirlenmesinde bir ölçü olarak ele alınmaktadır (Rasane ve ark, 2015). Ayrıca tane boyutu un verimine doğrudan etkiye sahip olduğundan öğütme sanayinde büyük öneme sahiptir (Doehlert ve ark., 2006). Vilaró ve ark. (2004), yapmış oldukları çalışmada, tane boyunun eski çeşitlerde 6.90-10.72 mm, yeni çeşitlerde $8.12-10.18 \mathrm{~mm}$ ve seçilen hatlarda 8.69-10.36 mm arasında değiştiğini ve bu özelliğin genotipik farklılıktan kaynaklandığını bildirmişlerdir. Mut ve ark. (2018b) yulaf çeşitlerinde salkımın farklı kısımlarından elde edilen tanelerin fiziksel ve kimyasal içeriklerini inceledikleri çalışmada tane boyu ve eni üzerine genotip, tanenin salkımdaki konumu ve yılların etkili olduğunu bildirmişlerdir. Çalışkan ve Koç (2019) 164 yulaf genotipi ile yaptıkları çalışmada yerel genotiplerde ortalama tane boyu ve enini sırasıyla $15.49 \mathrm{~mm}$ ve $2.63 \mathrm{~mm}$ olarak belirlemişlerdir.

\section{İç Oranı}

Yulafta iç oranı ögütme teknolojisinde önemli kalite özelliklerinden birisi olup yüksek olması istenmektedir (Doehlert ve ark., 1999). Birleştirilmiş yılların analizine göre, iç oranı bakımından yıllar ve genotipler arasında istatistiki olarak önemli $(\mathrm{P}<0.01)$ farklar tespit edilmiştir. Ayrıca bu özelliğin yıl $\times$ genotip interaksiyonundan istatistiki olarak $(\mathrm{P}<0.01)$ etkilendiği belirlenmiştir (Çizelge 1). Çalışmada genotiplerin iç oranı \% 51.85 (G118) ile 77.78 (G116) arasında değişmiş ve ortalaması \% 68.03 olmuştur. Genotiplerin \% 50'sinin (136 genotip) iç oranı \% 65-70 sınıf aralığında yer almıştır. İç oranı çeşitlerde \% 67.08, popülasyonlarda ise \% 68.09 olarak belirlenmiştir (Şekil 4). İç oranı birinci yıl (\% 69.58) ikinci yıldan (\% 66.51) daha yüksek olmuştur (Şekil 5). Yapılan bir çalışmada yulafın iç oranına, genotip ve çevrenin etkisinin hemen hemen eşit olduğu bildirilmiştir (Doehlert ve ark., 2001). Welch ve 
ark. (2000), iç oranının \% 32.7-62.1 arasında değiştiğini, bu özellik bakımından yulafta tür içinde ve türler arasında büyük varyasyonun olduğunu vurgulamışlardır. Buerstmayr ve ark. (2007), 120 yulaf çeşidinde yaptıkları çalışmada, çeşitler arasında önemli varyasyonun olduğunu ve iç oranının \% 62.073.5 arasında değiştiğini ifade etmişlerdir. Yulafta kavuz oranının yüksek olmasının, bu bitkinin hayvan yemi olarak kullanımını sınırladığı bildirilmiştir (Sainio ve ark., 2004).
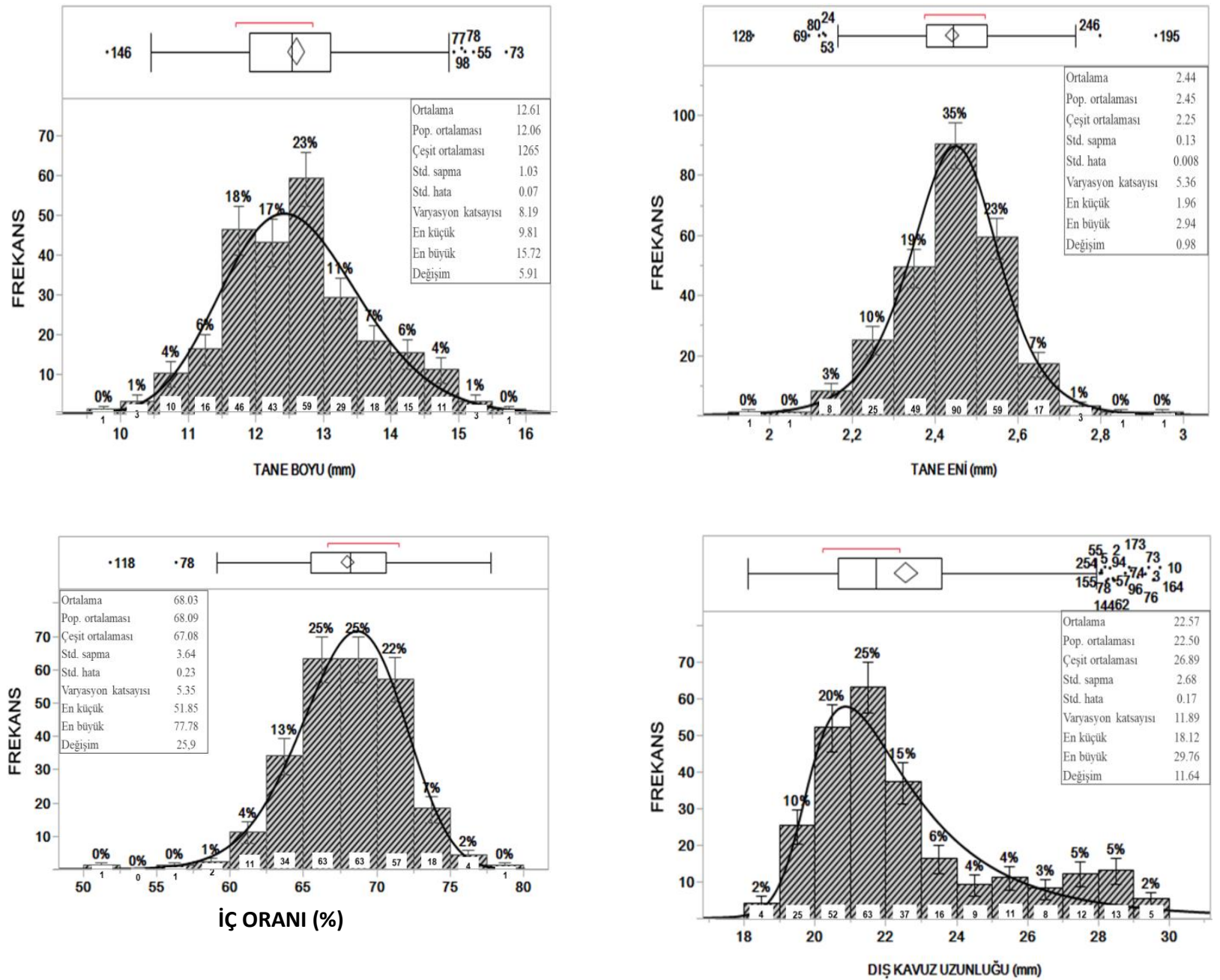

Şekil 4. 255 adet yulaf genotipinin tane boyu, tane eni, tane/kavuz oranı ve diş kavuz uzunluğunu gösteren histogram grafikleri ve tanımlayıcı istatistik verileri

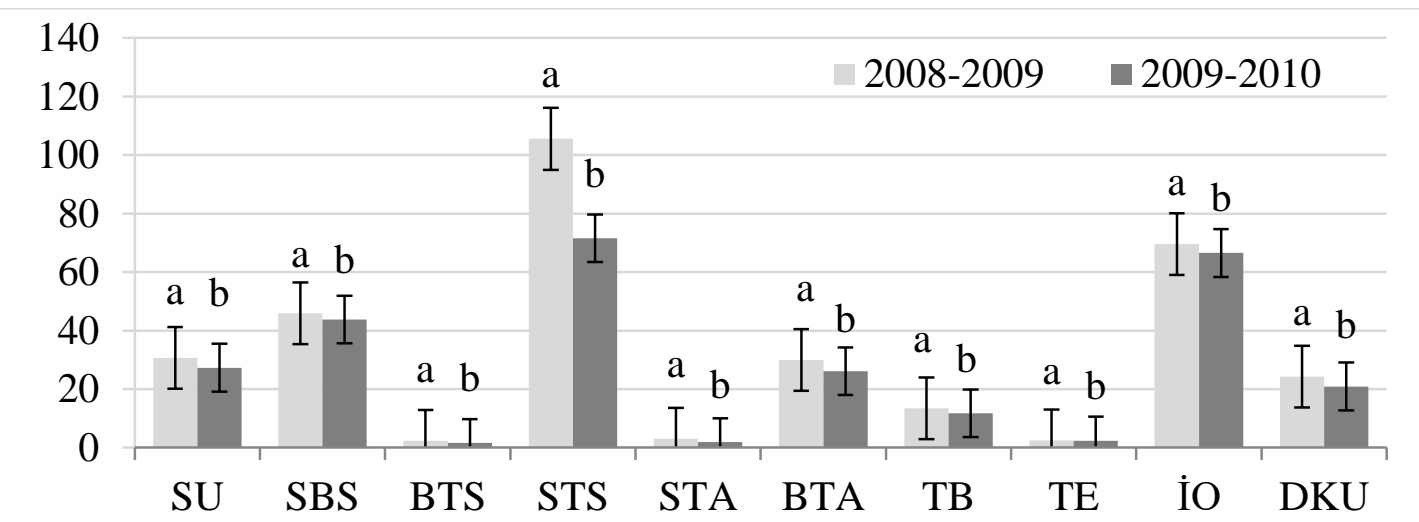

Şekil 5. Yulaf genotiplerinin 2008-2009 ve 2009-2010 yıllarına ait incelenen özelliklerinin ortalama değerleri (SU: Salkım uzunluğu, SBS: Salkımda başakçık sayısı, BTS: Başakçıkta tane sayısı, STS: Salkımda tane sayısı, STA: Salkımda tane ağırlığı, BTA: Bin tane ağırlı̆̆ı, TB: Tane boyu, TE: Tane eni, T\KO: Tanelkavuz oranı, DKU: Dış kavuz uzunluğu) 


\section{Dıș Kavuz Uzunluğu}

İki yılın birleştirilmiş analizine göre, dış kavuz uzunluğu bakımından yıllar ve genotipler arasında önemli ( $\mathrm{P}<0.01)$ farklar belirlenmiştir (Çizelge 1). Genotiplerin dış kavuz uzunluğu 18.12 (G1) ile 29.76 $\mathrm{mm}$ (G10) arasında değişmiş ve ortalama $22.57 \mathrm{~mm}$ olmuştur. Genotiplerin \% 25'sinin (63 genotip) diş kavuz uzunluğu 21-22 mm sınıf aralığında yer almıştır. Dış kavuz uzunluğu çeşitlerde $26.89 \mathrm{~mm}$, populasyonlarda ise $22.50 \mathrm{~mm}$ olarak belirlenmiştir (Şekil 4). Dış kavuz uzunluğu birinci yıl (24.24 mm) ikinci yıldan $(20.90 \mathrm{~mm}$ ) daha düşük olmuştur (Şekil 5). Vilaro ve ark. (2004) yapmış oldukları çalışmada, dış kavuz uzunluğunun genotipik farklılıktan kaynaklandığını ve dış kavuz uzunluğunun eski çeşitlerde 19.80-29.30 mm, yeni çeşitlerde 23.40-28.30 mm ve seçilen hatlarda 23.52-28.02 mm arasında değiştiğini bildirmişlerdir. Çalışkan ve Koç (2019) yaptığı çalışmada dış kavuz uzunluğunun genotipler arasında önemli farklar gösterdiğini ve dış kavuz uzunluğunun yerel genotipler ve çeşitlerde sırasıyla $24.8 \mathrm{~mm}$ ve $21.94 \mathrm{~mm}$ olduğunu bildirmişlerdir.

Çizelge 2. Birleştirilmiş verilere göre incelenen özelliklerin en yüksek ve en düşük değer gösterdiği beş genotip

\begin{tabular}{lll}
\hline İncelenen özellikler & En yüksek & En Düşük \\
\hline Salkım uzunluğu & $12,14,103,196,230$ & $50,144,145,164,182$ \\
Salkımda başakçık sayısı & $68,75,109,118,126$ & $131,144,145,216,244$ \\
Başakçıkta tane sayısı & $93,96,98,144,145$ & $11,69,202,205,221$ \\
Salkımda tane sayısı & $53,68,75,118,126$ & $131,206,216,244,247$ \\
Salkımda tane ağırlığı & $75,83,109,118,126$ & $133,142,149,160,244$ \\
Bin tane ağırlığı & $70,73,93,96$, Yeşilköy- 330 & $56,66,67,111,146$ \\
Tane boyu & $55,73,77,78,98$ & $130,146,196,228,234$ \\
Tane eni & $50,109,181,195,246$ & $24,53,69,80,128$ \\
Tanelkavuz oranı & $105,116,243,244,251$ & $55,78,118,151,164$ \\
Dış kavuz uzunluğu & $3,10,73,76,164$ & $1,53,75,133,152$ \\
\hline
\end{tabular}

\section{İncelenen Özellikler Arasındaki İlişkiler}

İki yıllık birleştirilmiş verilere göre incelenen özellikler arasındaki korelasyon katsayıları Çizelge 3'de verilmiştir. Tahıllarda verim, $\mathrm{m}^{2}$ ' deki bitki sayısı, salkımda başakçık sayısı ve salkımda tane sayısı gibi birçok farklı özellikten olumlu ya da olumsuz etkilenen karmaşık bir özelliktir (Kapoor ve ark., 2011). Çizelge 3'e göre, salkım uzunluğu ile SBS ( $\left.\mathrm{r}=0.482^{* *}\right)$, STS $\left(\mathrm{r}=0.419^{* *}\right)$, STA $(\mathrm{r}=0.169 * *)$ ve İO $(\mathrm{r}=0.209 * *)$ arasında olumlu ve önemli, BTS $(\mathrm{r}=-0.295 * *)$, BTA $(\mathrm{r}=-0.541 * *)$, TB $(\mathrm{r}=-0.262 * *)$, TE $(\mathrm{r}=-$ $0.348 * *)$ ve DKU ( $\mathrm{r}=-0.429 * *)$ arasında olumsuz ve önemli ilişki belirlenmiştir. Salkımda başakçık sayısı ile STS $(\mathrm{r}=0.927 * *)$ ve STA $\left(\mathrm{r}=0.723^{* *}\right)$ arasında olumlu ve önemli, BTS $(\mathrm{r}=-0.338 * *)$, BTA $(\mathrm{r}=-$ $0.480 * *)$, TB $(\mathrm{r}=-0.271 * *)$, TE $(\mathrm{r}=-0.286 * *)$ ve DKU $(\mathrm{r}=-0.422 * *)$ arasında olumsuz ve önemli ilişki belirlenmiştir. Başakçıkta tane sayısı ile STA $\left(\mathrm{r}=0.178^{* *}\right)$, BTA $(\mathrm{r}=0.379 * *)$, TB $(\mathrm{r}=0.444 * *)$, TE $(\mathrm{r}=0.145 *)$ ve DKU $(\mathrm{r}=0.544 * *)$ arasında önemli ve olumlu, İO $(\mathrm{r}=-0.458 * *)$ arasında olumsuz ve önemli ilişki belirlenmiştir. Salkımda tane sayısı ile STA $(\mathrm{r}=0.837 * *)$ arasında olumlu ve önemli, BTA ( $\mathrm{r}=-$ $0.379 * *)$, TB $(\mathrm{r}=-0.141 *)$, TE $(\mathrm{r}=-0.260 * *)$ ve DKU $(\mathrm{r}=-0.279 * *)$ arasında olumlu ve önemli ilişki belirlenmiştir. Salkımda tane ağırlı̆̆ı ile BTA $\left(\mathrm{r}=0.138^{*}\right)$ arasında olumlu ve önemli ilişki belirlenirken, İO $\left(\mathrm{r}=-0.212^{*}\right)$ arasında olumsuz ve önemli ilişki belirlenmiştir. Bin tane ağırlığ ile TB $\left(\mathrm{r}=0.449^{* *}\right)$, TE $\left(\mathrm{r}=0.476^{* *}\right)$ ve DKU $\left(\mathrm{r}=0.582^{* *}\right)$ arasında olumlu ve önemli, İO $\left(\mathrm{r}=-0.211^{* *}\right)$ olumsuz ve önemli ilişki belirlenmiştir. Tane boyu ile TE $\left(\mathrm{r}=0.357^{* *}\right)$ ve DKU $\left(\mathrm{r}=0.603^{* *}\right)$ arasında önemli ve olumlu, İO ( $\mathrm{r}=-$ $\left.0.387^{* *}\right)$ arasında olumsuz ve önemli ilişki belirlenmiştir. Tane eni ile DKU ( $\left.\mathrm{r}=0.324^{* *}\right)$ arasında olumlu ve önemli ilişki belirlenirken, iç oranı ile DKU ( $\left.\mathrm{r}=-0.416^{* *}\right)$ arasında olumsuz ve önemli ilişki belirlenmiştir. 
Çizelge 3. İki yıl süreyle değerlendirilen 255 yulaf genotiplerinin incelenen özellikler arasındaki Pearson korelasyon katsayıları ve ilişkileri

\begin{tabular}{|c|c|c|c|c|c|c|c|c|c|}
\hline & SU & SBS & BTS & STS & STA & BTA & TB & $\mathrm{TE}$ & $\mathrm{T} \backslash \mathrm{KO}$ \\
\hline SBS & $0.482 * *$ & & & & & & & & \\
\hline BTS & $-0.295 * *$ & $-0.338 * *$ & & & & & & & \\
\hline STS & $0.419 * *$ & $0.937 * *$ & -0.026 & & & & & & \\
\hline STA & $0.169 * *$ & $0.723 * *$ & $0.178 * *$ & $0.837 * *$ & & & & & \\
\hline BTA & $-0.541 * *$ & $-0.480 * *$ & $0.379 * *$ & $-0.379 * *$ & $0.138 *$ & & & & \\
\hline $\mathrm{TB}$ & $-0.262 * *$ & $-0.271 * *$ & $0.444 * *$ & $-0.141 *$ & 0.092 & $0.449 * *$ & & & \\
\hline $\mathrm{TE}$ & $-0.348 * *$ & $-0.286 * *$ & $0.145^{*}$ & $-0.260 * *$ & 0.003 & $0.476 * *$ & $0.357 * *$ & & \\
\hline $\mathrm{T} / \mathrm{KO}$ & $0.209 * *$ & 0.061 & $-0.458 * *$ & -0.081 & $-0.212 *$ & $-0.211 * *$ & $-0.387 * *$ & 0.005 & \\
\hline DKU & $-0.429 * *$ & $-0.422 * *$ & $0.544 * *$ & $-0.279 * *$ & 0.010 & $0.582 * *$ & $0.603 * *$ & $0.324 * *$ & $-0.416 * *$ \\
\hline
\end{tabular}

SU: Salkım uzunluğu, SBS: Salkımda başakçık sayısı, BTS: Başakçıkta tane sayısı, STS: Salkımda tane sayısı, STA: Salkımda tane ağırlı̆̆ı, BTA: Bin tane ağırlığı, TB: Tane boyu, TE: Tane eni, T\KO: Tanelkavuz oranı, DKU: Dış kavuz uzunluğu

Kapoor ve ark. (2011) korelasyonun, ıslah programlarında özellikler arasındaki ilişkilerin belirlenmesinde çok önemli olduğunu bildirmiştir. Buerstmayr ve ark. (2007) yulafta tane verimi ile verim bileşenleri arasında önemli korelasyonlar olduğunu belirlemiş ve bitki boyu, bitki başına salkım sayısı ve salkım başına tane sayısının da tohum verimi ile pozitif yönde ilişkili olduğunu bildirmiştir. Aynı araştırıcı salkımda başakçık sayısı ile başakçıkta tane sayısı arasında önemli ve olumlu ilişki olduğunu bildirmiştir. Vaisi ve Golparvar (2013) yulafta yaptıkları çalışmada salkımda tane sayısı ile bin tane ağırlığı arasında olumsuz ve önemli ilişki olduğunu bildirmişlerdir. Brunova ve ark. (2014) iki yıl süre ile yaptığı çalışmada her iki yılda da salkımda tane sayısı ile salkımda tane ağırlığı arasında pozitif ve önemli ilişki olduğunu bildirmişlerdir. Sarı ve Ünay (2015) salkım uzunluğu ile salkımda başakçık sayısı, salkımda tane sayısı ve salkımda tane ağırlığı arasında olumlu ve önemli ilişki belirlerken, salkım boyu ile bin tane ağırlığı ve tane iriliği arasında olumsuz ve önemli ilişki belirlemişlerdir. Aynı araştırıcılar, verim ile bin tane ağırlığı, tane iriliği, salkımda başakçık sayısı, salkımda tane sayısı, salkımda tane ağırlığı arasında önemli pozitif ilişkilerin olduğu bildirmişlerdir (Sarı ve Ünay, 2015). Kaziu ve ark. (2019) tane verimi ile salkım uzunluğu ve salkımda tane sayısı arasında, salkım uzunluğu ile salkımda tane sayısı arasında olumlu ve önemli ilişki olduğunu bildirmişlerdir. Ayrıca, Kaziu ve ark. (2019) salkım uzunluğu ve salkımda tane sayısı arttıkça bin tane ağırlığının azaldığını bildirmişlerdir. Dumlupınar ve ark. (2017) bitki boyu, salkım uzunluğu, salkımda tane sayısı, salkımda tane ağırlığı ve bin tane ağırlığının tane verimini artırmada önemli bir seleksiyon kriteri olduğunu vurgulamışlardır. Çalışmada elde ettiğimiz bulgularda da benzer sonuçlar elde edilmiş ve incelediğimiz özelliklerin yulafta verimi iyileştirmek için seleksiyonda önemli özellikler olduğu görülmüştür.

\section{SONUÇ}

Orta ve Batı Karadeniz Bölgesinden toplanan çok sayıda yerel yulaf genotipi ile yapılan bu çalışmada incelenen bütün özellikler bakımından genotipler arasında çok önemli varyasyonun olduğu belirlenmiştir. Popülasyonun dağılımını gösteren histogram grafikleri toplanan yulaf materyalinin oldukça zengin bir genetik tabana sahip olduğunu, bu genotiplerin çeşit geliştirmeye yönelik seleksiyon çalışmalarında ya da bazı özelliklerinden dolayı seçilerek melezleme programlarında kullanılabileceğini göstermiştir. 


\section{TEŞEKKÜR}

Bu çalışma Türkiye Bilimsel ve Teknolojik Araştırma Kurumu (TÜBİTAK) tarafından TOVAG $107 \mathrm{O} 208$ numaralı proje ile desteklenmiştir.

\section{Çıkar Çatışması}

Makale yazarları aralarında herhangi bir çıkar çatışması olmadığını beyan ederler.

\section{Yazar Katkısı}

Yazarlar makaleye eşit oranda katkı sağlamış olduklarını beyan eder.

\section{KAYNAKLAR}

Anonim, 2019a. The Food and Agriculture Organization. http://www.fao.org/faostat/en/\#data (Erişim Tarihi: 11. 12. 2020)

Anonim, 2019b. Türkiye İstatistik Kurumu, https://biruni.tuik.gov.tr/medas/?kn=92\&locale=tr (Erişim Tarihi: 11.12.2020)

Batalova GA, Changzhong R, Rusakova II, Krotova NV, 2010. Breeding of Naked Oats. Russian Agricultural Sciences, 36(2): 93-95.

Boyle R, Corke F, Howarth C, 2015. Image-Based Estimation Of Oat Panicle Development Using Local Texture Patterns. Functional Plant Biology, 42(5): 433-443.

Brunava L, Alsıņa, I, Zute, S. 2014. Oat Grain Yield Variations Associated With Productivity Parameters Among Oat Cultivars Grown in Latvia. Fifth International Scientific Agricultural Symposium Agrosym 2014, Bosnia and Herzegovina, Jahorina, October 23-26, pp: 138-144.

Buerstmayr H, Krenn N, Stephan U, Grausgruber H, Zechner H, 2007. Agronomic Performance and Quality of Oat (Avena sativa L.) Genotypes of Worldwide Origin Produced under Central European Growing Conditions. Field Crops Research, 101(3): 343-351.

Çalıskan M, Koç A, 2019. Batı Akdeniz Bölgesi'ne Ait Yerel Yulaf Genotiplerinin Morfolojik Karakterizasyonu. Tarla Bitkileri Merkez Araştırma Enstitüsü Dergisi, 28(1): 7-18.

Diederichsen, A, 2008. Assessments of Genetic Diversity Within a World Collection of Cultivated Hexaploid Oat (Avena sativa L.) Based on Qualitative Morphological Characters. Genetic Resources and Crop Evolution, 55(3): 419-440.

Doehlert DC, Mcmullen MS, Baumann RR, 1999. Factors Affecting Groat Percentage in Oat. Crop Sciences, 39:1858-1865.

Doehlert DC, Mcmullen, MS, Hammond, JJ, (2001).Genotyping and Environmental Effects on Grain Yield and Quality of Oat Grown in North Dakota. Crop Sci., 41:1066-1072.

Doehlert DC, Mcmullen MS, Jannınk JL, (2006). Oat Grain/Groat Size Ratios: A Physical Basis for Test Weight. Cereal Chemistyr, 83(1): 114-118.

Dumlupınar Z, Tekin A, Herek, S, Tanrıkulu, A, Dokuyucu T, Akkaya A, 2017. Türkiye Kökenli Yulaf Genotiplerinin Bazı Tarımsal Özellikler Bakımından Değerlendirilmesi. Türk Tarım-Gıda Bilim ve Teknoloji dergisi, 5(7): 763-772.

Dumlupinar Z, Kara R, Dokuyucu, T, Akkaya A, 2012. Correlation and Path Analysis Of Grain Yield And Yield Components Of Some Turkish Oat Genotypes. Pakistan Journal of Botany, 44(1): 321-325.

Dumlupinar Z, Maral H, Rukiye K, Dokuyucu T, Akkaya A, 2011. Evaluation of Turkish Oat Landraces Based on Grain Yield, Yield Components and Some Quality Traits. Turkish Journal of Field Crops, 16(2): 190196.

Erbaş ÖD, Mut Z, 2013. Saf Hat Yulaf Genotiplerinin Tarımsal Ve Bazı Kalite Özelliklerinin Belirlenmesi. 10. Tarla Bitkileri Kongresi, Konya, 19-13 Eylül, pp: 821-829.

Federer WT, 2005. Augmented split block experiment design. Agron. J. 97(2): 578-586.

Finnan J, Burke B, Spink J, 2019. The Plasticity of the Oat Panicle and Associated Changes in Leaf Area and Grain Weight. Field Crops Research, 242: 107592.

JMP, 2007. JMP User Guide, Release 7 Copyright $@$ 2007, SAS Institute Inc., Cary, NC. 
Kapoor R, Bajaj RK, Sidhu N, Kaur S, 2011. Correlation and Path Coefficient Analysis in Oat (Avena sativa L.). International Journal of Plant Breeding, 5(2): 133-136.

Kaziu I, Kashta F, Celami A, 2019. Estimation of Grain Yield, Grain Components and Correlations between Them in some Oat Cultivars. Albanian Journal of Agricultural Sciences, 18(1): 13-19.

Koeyer DL, Stuthman DD, Fulcher RG, Pomeranke GJ, 1993. Effects of recurrent selection for grain yield on oat kernel morphology. Crop science, 33(5): 924-928.

Krishna A, Ahmed S, Pandey HC, Kumar V, 2014. Correlation, Path and Diversity Analysis of Oat (Avena sativa L.) Genotypes for Grain and Fodder Yield. Journal of Plant Science \& Research, 1(2): 1-9.

Kutlu I, Gulmezoglu N, 2020. Morpho-agronomic Characters of Oat growing with Humic Acid and Zinc Application in Different Sowing Times. Plant Science Today, 7(4): 594-600.

Kün E, 1988. Serin iklim Tahılları S: 216. Ankara Üniversitesi Ziraat Fakültesi Yayınları, No: 1032, Ders Kitabı No: 299.

McBratney BD, Frey KJ, 1983. Inheritance of Tertiary Seed Development in Oats. Cereal Research Communications, 91-97.

Mut Z, Akay H, Erbaş Köse ÖD, 2018a. Grain Yield, Quality Traits and Grain Yield Stability of Local Oat Cultivars. Journal of Soil Science and Plant Nutrition, 18 (1): 269-281.

Mut Z, Akay H, Sezer İ, Gülümser A, Öner F, Erbaş Ö, 2011. Farklı Orijinli Yulaf (Avena sativa L.) Genotiplerinin Samsun Ekolojik Koşullarında Tarımsal ve Bazı Kalite Özelliklerinin Tespiti. 9. Tarla Bitkileri Kongresi, Bursa, 12-15 Eylül, pp: 88-93.

Mut Z, Erbaş Köse ÖD, Akay H, 2016. Grain yield and some quality traits of different oat (Avena sativa L.) genotypes. International Journal of Environmental and Agriculture Research, 2 (12): 83-88.

Mut Z, Erbaş Köse ÖD, Akay H, 2018b. Variation of Some Physical and Chemical Quality Traits of the Grains in Different Parts of The Oat Panicle. International Journal of Agriculture and Biology, 20: 268-276.

Nikoloudakis N, Bladenopoulos K, Katsiotis A, 2016. Structural Patterns and Genetic Diversity Among Oat (Avena) Landraces Assessed by Microsatellite Markers and Morphological Analysis. Genetic Resources and Crop Evolution, 63(5): 801-811.

Rasane P, Jha A, Sabikhi L, Kumar A, Unnikrishnan VS (2015) Nutritional Advantages of Oats and Opportunities for Its Processing as Value Added Foods. J Food Sci Technol., 52:662-675.

Sainio PP, Kontturi M, Rajala A, 2004. Impact Dehulling Oat Grain Improve Quality of On-Farm Produced Feed I. Hullability and Associated Changes in Nutritive Value and Energy Content. Agricultural and Food Science, 13: 18-28.

Sar1 N, Ünay A, 2015. Yulafta (Avena sativa L.) Tane Verimini Etkileyen Özelliklerin Belirlenmesi. Tarla Bitkileri Merkez Araştırma Enstitüsü Dergisi, 24(2): 115-123.

Sawicki J, (1984). The Structure of Yield Ġn Varieties And Strains of Oats, and The Contributions of Components of Yield in The Formatin of Grain Yield. Acta Agraria et Silvestria, Agraria, 23:59-77.

Sürek H, Valentıne J, 1996. Kültürü Yapılan Yulafta (Avena sativa L.) Bazı Kantitatif Karakterler Arasındaki İlişkiler ve Kalıtım Dereceleri. Ankara Üniversitesi Ziraat Fakültesi Tarım Bilimleri Dergisi, 2(3): 39-43.

Vaisi H, Golparvar AR, 2013. Determination of the Best Indirect Selection Criteria to Improve Grain Yield and Seed Weight in Oat (Avena sativa L.) genotypes. IJFAS, 2: 747-750.

Vilaró M, Rebuffo M, Miranda C, Pritsch C, Abadie TM, 2004. Characterization and Analysis of A Collection of (Avena sativa L.) from Uruguay. Plant Genet Res. News. 140:23-31.

Webster FH, 2012. Oat. In: R. Henry and P. Kettlewell (Eds) Cereal grain quality, Springer Science \& Business Media, Londan, UK, pp: 179-199.

Welch RW, Brown JCW, Leggett JM, 2000. Interspecific and Intraspecific Variation in Grain and Groat Characteristics of Wild Oat (Avena) Species: Very High Groat $(1 \rightarrow 3),(1 \rightarrow 4)-\beta$-D-glucan in an Avena Atlantica Genotype. Journal of Cereal Science, 31(3): 273-279. 